\title{
A Socio-Cultural Narrative of Homes for Older People in Eswatini: A Wellness Perspective
}

\author{
Thandi F. Khumalo ${ }^{1^{*} \quad \text { Maxwell C.C. Musingafi }}{ }^{2} \quad$ Rachael Mafumbabte $^{3}$ \\ 1.University of Eswatini, Department of Sociology and Social Work, Faculty of Social Sciences \\ 2.Zimbabwe Open University, Department of Development Studies, Faculty of Applied Social Sciences \\ 3.University of Eswatini, Department of Educational Foundations and Management, Faculty of Education
}

\begin{abstract}
This paper presents a narrative of socio-cultural perceptions of homes for old people in Eswatini and their impact on indigenous and cultural norms of the old generation who are the beneficiaries of these homes. On top of establishing that there is a paucity of published research on elderly care and support in Eswatini, the paper argues that the majority of old people still reside in the rural areas where indigenous socio-cultural values are strongly held. It also establishes evidence of growing economic shocks and rising inequality, all heightening oldage vulnerabilities. The government has not sufficiently responded to the needs of older people even with the constant advantage of the low population of older people in Eswatini. The paper argues that Eswatini needs interventions that are culturally appropriate for successes to be recorded in all aspects of development. It advocates for the UNESCO (1995-2012) model that calls for interventions that are culturally appropriate, gender and age responsive, grounded in human rights and involving people affected by the interventions. There is need for a care and support system that permits the elderly to remain in their homes.
\end{abstract}

Keywords: Older people, homes, Eswatini, socio-cultural, narratives

DOI: $10.7176 / \mathrm{JCSD} / 51-02$

Publication date:September $30^{\text {th }} 2019$

\section{Orientation}

Older people have traditionally been an important feature of family and society, and their knowledge and wisdom has been highly respected in society. Unravelling family structure and networks which traditionally provided safety networks for older people and children has inflicted myriad challenges of care and support for older people and children, necessitating alternative care and support mechanisms. One of the interventions currently under implementation is older people's homes in two locations in Eswatini.

The population of Eswatini during the 2017 census year was 1,093,238 and is projected to be 1,303,090 by 2030 (Swaziland Government, 2017). Unlike many developing countries in the world Eswatini is not experiencing a rapid growth of the ageing population. Contrary, there is a rapid and sustained population growth experienced in the population aged 14 years and below which was 387,473 making 35.6 percent of the total population (see Figure 1). The population percentage of 65 years and above was 5.5 in 2007, decreasing to 4 in 2017 (Swaziland Government, CSO, 2017).

Figure 1 shows the age structure of the population as characterised by a youthful population; by 2017 approximately $40 \%$ being under 15 years of age. Overall, $52 \%$ of the population is below the age of 20 years and with a potential to grow. The population is distributed along the horizontal axis, with males shown on the left and females on the right. The male and female populations are broken down into 5-year age groups represented as horizontal bars along the vertical axis, with the youngest age groups at the bottom and the oldest at the top.

Figure 1 Eswatini population by gender and age group in 2017

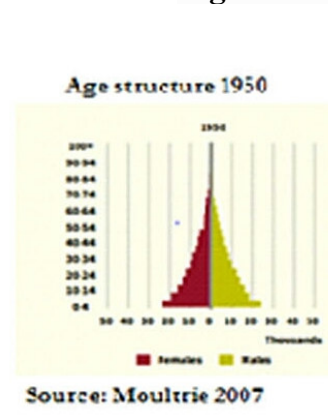

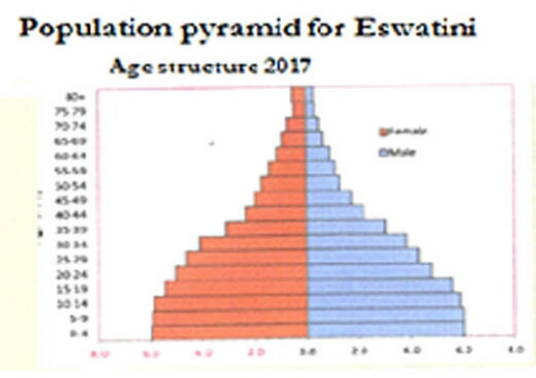

Source: EswatiniCSO 2017

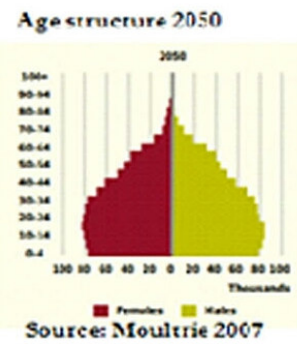

Source: Moultrie 2007

Figure 2 shows a bulging youthful population between the ages 0-14 years with a shrinking ageing population from 65 years and above. The ageing female population is exhibiting signs of longevity than their male counterparts. The shape of the population pyramid gradually evolves over time based on fertility, mortality, and international migration trends" (Index Mundi, 2016). The thinning older population has both positive and negative implications in their care and support. On the positive side the older population is small and 
manageable for rolling out programmes and releasing the necessary resources. On the negative side the bulging young population directs resources and programmes away from the older populations with priority given to education and other needs of young people.

Figure 2: Swaziland Population distribution pyramid

\begin{tabular}{|c|c|c|}
\hline & $65+\quad \square$ \\
\hline & & $15-64 \quad \square$ \\
\hline & & $0-14$ \\
\hline
\end{tabular}

Source: Country meters October 4, 2017

Figure 3 shows that the dependent population is more than half of the working population, meaning that the working population in Eswatini must provide for itself and cover the expenditure of children and aged persons (United Nations Statistics Division, 2016). Looking back to figure 2, 37.8 percent are children below the age of 15 years and 3.6 percent are the ageing population aged 65 years and above. The dependency ratio for children is 64.4 and the aged is 6.1 resulting in a total dependency ratio of 70.5 for Eswatini. All these people are dependent on the working population, creating a high dependency ratio of 69.22 in 2016 (ibid). Compounding the problem of dependency is the high unemployment rate among the youth who should be in active employment decreasing the number of working age adults to support older adults. Looking at figure 3 the decreased dependency by 2016 could be a reflection of the inability of working adults to take care of their family and other relatives concurrently.

Figure 3 Swaziland Age Dependency Ratio 1960-2016

Swaziland Age dependency ratio

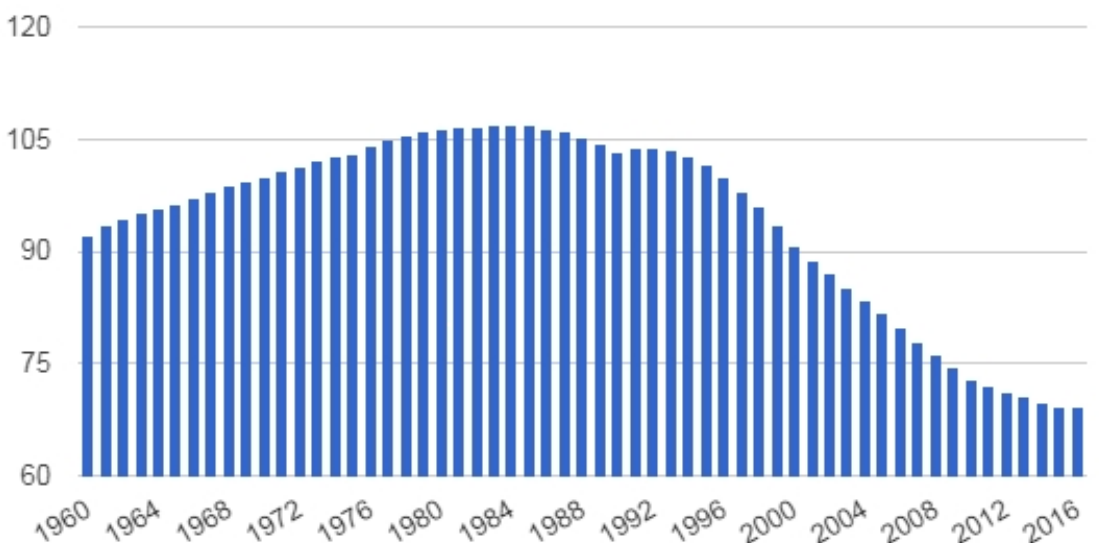

Source: TheGlobalEconomy.com, The World Bank

In Eswatini, active older people still work in family fields to contribute to the economic well-being of the household and the community. Thus, they remain economically active longer, partly because the cash transfer grants from Government do not meet all their basic needs. Dependency in this respect has to be qualified as older people are not in the same category of dependency as children below the age of 15 years.

Life expectancy for Eswatini, according to World Health Organization (WHO) (2014) published data is estimated at 58.9 years; for females it is 61.1 and 56.6 for males (WHO, 2014). The five top contributing killer diseases are HIV and AIDS, stroke, pneumonia, tuberculosis and diabetes.

Notably, in poverty statistics there is an overrepresentation of the older people making them vulnerable and unable to support themselves in the changing economic situation. Therefore, the care and support of older people has become a big concern for government and society at large. HelpAge International (2004:5) asserts that poverty and social exclusion are the major challenges facing older persons (cited in Dhemba, 2015). Furthermore, Dhemba (ibid) contends that "many older people have been self-sustaining members of society and have developed problems of adaptation only at an older age. Without support, accumulated interpersonal losses (such as the loss of a spouse, friends, families, familiar environment, job income, physical health) threaten the fulfilment of their daily living needs and life satisfaction (Dhemba, 2015).

Against this background it can be argued that there are good intentions behind the unprecedented move to 
establish homes for older people in the kingdom of Eswatini. The major objective is giving care and support to older people who fall largely in the population of vulnerable and poor citizens. The initial reaction by Emaswati on the proposal of homes for older people produced mixed feelings, considering the socio-cultural implications of uprooting an adult liSwati from their home environment. However, understanding the motivation enables internalisation of the new concept and conceptualising it differently. An analysis of how best the concept could work in the context of Eswatini is tabled later in this paper. This paper will hopefully inform policy and planning initiatives on homes for older people in Eswatini.

Eswatini is known for the practice of indigenous and cultural traditions. The majority of older people still reside in rural areas where indigenous socio-cultural values are strongly held. There is evidence of growing economic shocks and rising inequality, all heightening old-age vulnerabilities. Eroding income and support is affecting the wellbeing of households with children and older persons. Some older people rely on the old age grant as the main source of income, which is E440 (440 Emalangeni) per month (approximately US\$31) US\$1.04 per day $(\$ 1=$ E14, 2018 calculations). Persistent drought in some regions of the country particularly Lubombo has exacerbated the food security situation making reliance on farming untenable. These situations have triggered an initiative for establishing homes for the older people to cushion them against harsh living conditions, neglect and exclusion from mainstream society.

Eswatini is classified as a lower middle income economy (World Bank, 2018). Life expectancy at birth increased from 49 in 2014 to 57.75 in 2016 projected to increase to 60 by 2022 (United Nations Statistics Division, 2018). Unemployment is estimated at 26.40\% in 2018 from 28\% in 2014 (Index Mundi, 2018). Gini co-efficient from 48 to 45 in 2017 (Government of Swaziland, 2013). Population living below \$2 per day from $63 \%$ in 2014 to $56 \%$ in 2017 (Government of Swaziland, 2013).

With $63 \%$ of the population living on less than E20 per day, the country not only needs economic growth to create more jobs but also a social welfare system that protects the unemployed, the injured, the poor and those vulnerable through age or disability (Government of Swaziland, 2013). The government action plan further alluded to a residential facility for vulnerable groups constructed in Mankayane in 2015 and a residential facility for older people in the same location in 2016 (ibid).

The government of Eswatini Plan of Action 2013-2018 suggests that historically Eswatini society has been a caring one with communities using traditional methods of extending help and protection to the needy. The objective is not to move away from this culture, but to "continue to find ways of reviving this culture" (Government of Swaziland, 2013:12).

\section{Statement of the problem}

Traditional norms on family care of older people have unravelled in modern society with the younger generation either living away from their nuclear and extended families and/or the fading respect they once held for the older people in society. Thus, alternative methods of care need to be sort that will not greatly depart from the traditional models of care and support. Older people have ancestral beliefs and connections to their homes. As such, taking them away from their homes depresses them making them feel disconnected to their ancestral roots. Consequently, any kind of intervention, support and care needs to be home based to avoid uprooting them from their homes, referred to as aging in place in some literature. Nonetheless, young people, particularly grandchildren do not want to be burdened by taking care of older people. In fact, they have abdicated from supporting and caring for their own children. In South Africa the young people have dubbed the principle of taking care of family and kin as the "black tax" which most are not keen to adapt. Studies undertaken in Eswatini have confirmed that older people in Eswatini are amongst the most vulnerable to poverty and yet there are limited safety nets to safeguard them against all forms of vulnerabilities. What then is the way forward for Eswatini?

\section{Methods}

This is a qualitative narrative study adopting a rigorous search for literature relevant for the study. It was conducted mainly through search engine www.google.com and government published data in the form of Census and Household Economic Surveys of 2017 and 2018 respectively; and Eswatini government website with publications from Philani Maswati, the charity organisation establishing a home at Dvokolwako and the Social Welfare office at the Deputy Prime Minister's Office.

\section{Analytical framework}

Drawing from Luppa et al. (2009) it is argued that older people prefer to remain in their homes because they are able to maintain the integrity of their social network, preserve environmental landmarks and enjoy life. Moreover, institutionalization is associated with several negative outcomes such as increased mortality, restricted quality of life as well as questionable quality of care (ibid). From this backdrop, it is argued that Eswatini hastened the implementation of a very culturally sensitive programme without adequate research establishing the predictors 
for institutionalisation, and a needs assessment of an elderly care system that does not involve institutionalisation. As suggested earlier in the case of Eswatini, poverty and destitution are the key predictors of institutionalisation, against other tried and tested options such as home based care and support. There is a sense of general unpreparedness in formulating the policy to address issues of ageing. Uncoordinated efforts have been expressed in other policies of health care and grants for vulnerable citizens.

\section{Where do the elderly people live and who cares for them?}

Evidence from Household Income and Expenditure Survey (HIES, 2018) confirms that older people in Eswatini live in their homes with family or relatives and rarely on their own with occasional contact with a family member. Cases of total abandonment and isolation are beginning to appear, or increasingly getting media attention through community governing structures, faith based organisations, or neighbours who feel overwhelmed and burdened by caring for abandoned older people. Since the majority of older persons live in rural areas they own the homes they live in. These are homes that have housed generation to generation and are taken care of by the eldest member of the household. ULARN (2003:22) also found that access to land was not a problem for $60 \%$ of old people. Money and farming inputs were reported as serious problems rated at $84 \%$ and $69 \%$ respectively.

Some older persons live in urban areas in their own homes and some in informal settlements and in municipality governed residential areas. It is possible to find them in rental informal settlement housing for those that were previously workers in the urban areas. The challenges faced by older persons in the urban areas include the maintenance of their homes and servicing charges in rate payments to municipal authorities. Lack of income has proved it impossible for many older urban residents to honour their obligations to the municipal authorities. Hence, some live in constant fear of the possible attachment and sale of their homes by the municipal authorities for constant default in rates payment (Manzini City Council, not dated).

The Government of Swaziland introduced an Old Age Grant (OAG) in 2005. Documented evidence suggests that households spend old age benefits on essential services such as health care, education and essential household goods (Social Protection System and Economic Policy Research Institute, 2016). The argument is that OAG reduces poverty among older persons and generates positive impacts for local economies (strengthening both supply and demand) (Ibid). The reality is that older persons are poorer, and financially dependent on family and kin who are also overstretched.

\section{Social care for older people}

Older people wish to continue to live in their homes (Nicholl and Wilson, 2012). Old age is unfortunately often a time of loss (ibid). The potential losses include health and eventually life, due to increasing pathology; wealth due to termination of employment; companionship following bereavement (spouse, siblings and friends); independence due to acquired disabilities; impairment and renal function loss; and loss of independence (ibid). Further, as a consequence of the conditions above, they also experience unhappiness, grief, depression, suicide, increased incidences of illness, increased risk of accident, poverty, dependence and abuse, malnutrition and subnutrition, and hypothermia (ibid).

\section{Global perspective}

Globally it has been noted that improved hygiene and water supply and control of infectious diseases during the past century have greatly reduced the risk of premature death of older people worldwide (Ramashala, not dated:1). Consequently, this has caused an unprecedented global demographic revolution with the proportion of world's population aged 60 and over increasing more rapidly than in any previous era. Nonetheless, the contrary is true for Eswatini in that the population of older people has not significantly increased over many decades, remaining at plus / minus five percent. What is similar to most developing countries is that "...most of the poor still live in poverty" (ibid). Thus, large segments of the population continue to live at the margins. Furthermore, the traditional forms of care available to older generations [like the extended family support system] ... are under threat (Kalache, 1991 cited in Ramashala, ibid). This is largely because families have suffered from the impact of social change, including urbanization, geographic spread, the trend towards nuclear families and the participation of active household members in the workforce (ibid). It is important to note that families feel the strain of living and caring for older people with chronic and complex problems, and resort to institutionalising those who require more extensive care. Alternatively the family's social and migration for employment livelihood opportunities often lead to children unable to provide the necessary care; and with HIV and AIDS pandemic the caring strain has largely fell on older people where the younger generations are falling sick and dying, exacerbating the conditions of living and quality of life of grandparents (ibid).

Ramashala (n.d:2) recommends that policy considerations should take into account a broad-based approach that distinguishes between the well and active elderly, the disabled elderly, and the frail elderly. Intervention options should consider inter-sectoral structures and multidisciplinary strategies to ensure that older people are 
physically and psychologically well for as long as possible (ibid:3). Consequently, this would entail empowering families and local communities with resources and technical assistance to care for older persons in the community (ibid). It is no doubt that research including baseline studies need to be prioritised to "identify and modify, where possible, the broad range of high-risk situations that have long-term and devastating effects on older people" (ibid)

\section{Strategies to improve the care of older people}

Old Age Grant (OAG) is the largest cash transfer programme in Eswatini, and has the potential to have a greater impact on poverty (The World Bank, 2012), with enough "political will". OAG was introduced by the Government of Swaziland (now Eswatini) in 2005 to cushion the impact of the loss of support on older people resulting from deaths of their children and the increasing burden of caring for orphaned grandchildren (ibid).

Reports from the Department of Social Welfare (DSW) suggest that OAG has had a positive impact on beneficiaries' lives but not contributed much in terms of reducing poverty because a significant share of OAG resources go to non-poor households (The World Bank, 2012). In addition, administrative costs of disbursing $\mathrm{OAG}$ and other safety nets programmes are high relative to other countries.

Identifying and targeting beneficiaries is a recurring problem of all social grant schemes in Eswatini. There is lacking integration and coordinating mechanisms for application procedures and eligibility criteria, and these multiple targeting mechanisms increase administration costs (The World Bank, 2012).

The targeting criteria for many programmes are subjective, which increases the likelihood of inclusion and exclusion errors (The World Bank, 2012) increasing corruption and nepotism challenges. Developing more objective and transparent targeting mechanisms could significantly reduce the problems that can result in inclusion and exclusion errors (ibid).

The Government of Eswatini in 2016 introduced a project on Technical Assistance for Development of a Social Protection System in Swaziland. The exercise was supported through funding from the European Union (EU). The overall objective was to support the development of a social protection system in Eswatini; that is more efficient, sustainable and accountable throughout the lifecycle. Progress was made in terms of laying down the framework, however minimal successes have been achieved in terms of the buy in by major stakeholders who are already in social protection service provision.

\section{Care for older people in Eswatini}

\subsection{Swaziland Hospice at Home (SHAH)}

SHAH home based care delivers services via 4 visiting nurses who travel individually to the four regions of Swaziland: Manzini, Hhohho, Lubombo and Shiselweni. The nurses drive to each region daily to provide medical treatment, consultation, counseling, prescribing and dispensing of medication and home based care supplies (disposable napkins, gloves, disinfecting solution (Jik), sunlight (soap) and Vaseline), and bereavement counseling to family members (SHAH,n.d.).

The nurses also provide these services to patients who are able to travel, with the assistance of community care givers to wayside clinics, by appointment. For patients who are bed ridden they receive services at their homes. However, at times, the nurses must leave their vehicles parked and walk to the homes of their patients due to poor roads, especially in the rural areas. Thus, making home visits and delivery very difficult (SHAH, n.d).

Of the four regions in Eswatini, the Manzini region has recorded a high proportion of terminally ill patients as compared to the other three regions of Eswatini with 9922 patients amounting to a proportion of $23.31 \%$ (SHAH, n.d). The Manzini region was followed by the Hhohho region with 7106 patients constituting 16.70\%, and then the Lubombo region with 5707 patients making up 13.41\%. Lastly the Shiselweni region recorded a total number of 4056 patients which constitutes a low of $9.53 \%$. The remaining $37.05 \%$ of patients were recorded at the clinic (ibid).

The recorded high of terminally ill patients in the Manzini region is due to the influx of people from other regions in Eswatini and from other countries like Mozambique. This influx can be attributed to the fact that the Manzini city is a commercial capital situated next to the Matsapha Industrial Town where a lot of people are employed in the factories. The rate at which people flock to the Manzini city has put so much pressure on employment and other services offered in the city and has resulted in poverty taking a toll amongst the people (SHAH, n.d).

The Shiselweni region recorded the lowest number of terminally-ill patients most likely as a result of being the least developed region in the country with little or no infrastructure. This region, with a high number of impoverished people, lacks basic infrastructure such as roads and health facilities, which makes it difficult for people to access health care. Therefore, it is challenging for SHAH nurses on fieldwork in the Shiselweni region to access patients to give them medical attention (SHAH, n.d). There are likely more terminally-ill people who need access to services despite the low number reported. 


\subsection{Mankayane Old Age Home}

This is the first home for older people in Eswatini initiated by the Government through the Deputy Prime Minister's (DPMO) office, Department of Social Welfare (DSW). The home is located in a Regional Town Mankayane which is a small town with a mix of urban and rural features and surroundings.

In June 2017 a local newspaper The Swazi Observer reported that phase 1 of the old age home is complete and ready for the first occupants. Phase 1 has four (4) units of three (3) bedroom houses, a canteen, semidetached two (2) bedroom houses for social workers who will be taking care of the older people (Observer on Saturday, 10 June 2017).

The eligibility criteria has been loosely defined by the DPMO to include senior citizens who are destitute, live alone and are vulnerable to neglect and abuse, and cater for those who have been totally abandoned by family and relatives and cannot afford any means of survival.

The facility aims to provide a decent and secure environment to live in, with social services such as health care facility rooms, medical emergency rooms, dining area and canteen, and around the clock security and care. These facilities are new and have not been utilised as yet because no older people have occupied the home.

It is proposed by DPMO that in future similar homes will be built in the other regions of the country. The home will also provide a halfway house for abused and disabled elderly people. Cases of assault, starvation, isolation by locking elderly people in confined spaces have been reported in the media and the DSW office (Observer on Saturday, 10 June 2017).

\subsection{Dvokolwako Old Age Home}

A second home was constructed in a rural community setting at Dvokolwako in the Hhohho Region. This is an initiative of a charity organisation started by Her Majesty the Queen Mother Philani Maswati Charity Organisation (PMCO) to cater for and take care of the needs of older people and orphaned children. The organisation has successfully assisted thousands of older people in Eswatini through food and blanket donations and started a project of developing houses for senior citizens in an area close to 15 hectors at Dvokolwako, in the Hhohho Region.

The design of the older citizen's housing is aimed to respond to the following requirements: arable land for self-sufficient farming businesses, producing fruit and vegetables that can be sold to fund healthcare and other amenities for residents. Residents would also be offered part-time employment within the farm which will make them feel part of the community. The objectives are stated as to provide its residents with a secure, relaxed and homely environment in which their care, well-being and comfort is of prime importance; and to provide a warm and caring atmosphere for its residents, and sensitive to the resident's ever-changing needs - medical/therapeutic, cultural, psychological, spiritual, emotional and social.

\section{Discussion}

Eswatini National Development Strategy (NDS-2022) proposes the following strategies regarding the elderly:

a) Institutional Support

- Encourage savings in the form of insurance and pension schemes.

- Provide recreational facilities for the elderly as part of infrastructural development.

b) Policy and Legislative Measures

- Review the government's public assistance policy with the aim of making the amount more realistic with the cost of living

- Develop a policy to address the criteria used to identify destitute and elderly people.

- Taxation incentives should be introduced to encourage individuals to care for the elderly.

c) Capacity Building

- Initiate and improve capacity building in all institutions working with the elderly.

- Government should sub-contract care services for the elderly

- Encourage, promote and strengthen the family unit.

d) Planning and Co-ordination

- Co-ordinate the activities of all organisations that support the destitute elderly to avoid duplication of effort.

- Develop an efficient information management system in order to improve the planning process.

Ever since the implementation of the NDS began in 1999 it has achieved only a fraction of the strategic objectives mentioned here, including the old age grant reviewed in 2017 and free medical attention at public health care centres for the elderly. The government has not sufficiently responded to the needs of older people even with the constant advantage of the low population of older people in Eswatini.

\subsection{Poverty}

Poverty is one major concern of older people and affects their health, education, self-esteem, quality of life and 
lifestyle (Okie, 1991 cited in Ramashala, n.d:5). Harper, 1988 cited in Ramashala (op cit) also noted that "health for the elderly may be conceptualised as the ability to live and function effectively in society and to exercise maximum self-reliance and autonomy; it is not necessarily the total absence of disease". Ramashala (ibid) notes that this definition is closely related to the World Health Organization, 1989 definition of viewing the health of older people as their level of functioning, including degree of fitness rather than extent of pathology, which may be used as a measure of the amount of services the elderly will need from the community.

Older people are consistently amongst the poorest in all societies, and their material security is one of the greatest preoccupations of old age (Ramasala, n.d: 6). Older people living in poverty find themselves socially excluded and isolated from decision-making processes. This affects not only their income and wealth but also contributes to poor housing, ill health and personal insecurity (ibid).

Economic shocks, rising inequality, demographic trends, accelerating urbanisation and increasing migration are all heightening old-age vulnerabilities (SPS \& EPRI, 2016) in Eswatini. Cultural beliefs and practices concerning social security have upheld that families take care of their own. This line of thinking has persisted more in theory than in practice, as families continue to suffer economic shocks which are a manifestation of national and global deteriorating economic situations. Older people are classified under vulnerable populations of society due to their frail physical condition and economic participation. It is believed that a sizeable population (ULARN, 2003) of older people live and care for grandchildren and great grandchildren while their parents work in the cities and some have become estranged from their families. The government and charity organisations have initiated social security programmes to help alleviate the plight of older people in Eswatini. The situation, in some cases, is beyond the control of the charitable organisations, and requires more systematic and sustainable social security mechanisms.

Studies on the vulnerability of older people in Eswatini (Kaseke 1997; Kaleeba 2002; Dlamini 2003; ULARN 2003, SPS \& EPRI 2016) have found that older people are vulnerable, face problems of isolation, neglect and abandonment by kin, live in dilapidated houses, care for grandchildren with meagre old age grant incomes, affected by HIV and AIDS pandemic as care givers and taking care of orphans, suffer numerous health problems, suffer sexual violence and exploitation, physical and emotional abuse, and mythical stereotypes associated with witchcraft and old age. Assistance in the form of food, clothing, farm inputs, and money is sporadic and often unsustainable thus contributing little towards alleviating the plight of older people (ULARN, 2003). A connected issue is that even where programmes for assisting older people were available, older people had no access to information about these programmes, and the criteria used to select beneficiaries was ad hoc and left to the discretion of rural health motivators who were sometimes subjective in their selection (ibid).

\subsection{Living arrangements and preferences of older people}

Africa used to be one of the world's best places to grow old (Maeir, 1992). Advanced age was regarded as a blessing and older people revered as sacred, the crucial link between the living and the ancestors, the holders of wisdom and culture (Maeir, 1992).But today, as with so much of African society, times are changing - and for older people, radically so. The growing influence of Western-style education, free-market economics and accelerated migration is putting Africa's traditional extended families under strain and people's ability to care for the elderly in jeopardy (ibid).

No baseline studies and systematic research has been conducted on the living arrangements of older people in Eswatini. Nevertheless, research from elsewhere in Africa cited in Ramashala (n.d :7) (Apt, 1985, 1991, 1992 , 1994, 1995, 1996; Addo 1972; Brown, 1984; Cox and Mberia, 1977) and ULARN 2003 in Eswatini recognises that any discussion of living arrangements in developing countries in general and Africa in particular must take into consideration a multiplicity of factors. Ageing occurs in a context that includes the needs and resources of individuals, their patterns of activities, their relationships with others and their attachments to their surroundings. Ageing interacts with all these aspects of the physical and social environment Ramashala, (op cit). Data and policies on the living arrangements are scanty in Eswatini making it difficult to make specific plans targeting older people.

"Demographic, socio-economic and cultural forces have redefined and altered the structure and functions of the family in...Swaziland. Urbanization has influenced family formation, led to shrinking or contracting of family size, and has largely impacted on the security and welfare support of dependants, particularly children and the elderly" (Khumalo, 2006). Further, HIV and AIDS have also greatly affected ... family structures and functions, increasing the vulnerability of families living in poverty in Swaziland" (ibid). Children and the elderly have assumed the roles of providers in their families.

Ramashala (n.d.:13) recommends options for elderly care and support to distinguish between the well and active elderly, the disabled elderly and the frail elderly, including other categories. To empower local communities with resources and technical expertise to care for older persons in the community, and this in turn means access to amenities ranging from water, sanitation, transport, housing, and access to health promotion, disease and disability-prevention strategies. In addition, have options for disabled older people who are living at 
home under the care of family members. He argues that studies have shown that care for disabled older people, is around the clock, and a burden and major stressor and in some cases results in neglect and abuse. Thus, every effort should be made by the health and welfare sectors to provide community-based supportive care to older people as well as to caregivers. Importantly, he points out that limited data available in Southern Africa and elsewhere indicate that the institutionalization of older people is not a recommended strategy.

Further, the frail elderly who require intensive around-the-clock care need several levels of care, ranging from the provision of community-based respite care to shorter-term hospitalization, specifically focusing on physical and psychological problems. Family support, in practice remains the most widely used survival strategy for the majority of the world's older people, whether in the context of extended families or co-residence of parents with adult children (Ramashala n.d.).

All these options are useful and very relevant for Eswatini. This paper draws on the conclusions made by Ramashala (n.d.:15) that, policy makers and planners should be aware that there must be a variety of living arrangements to meet the needs of the older population and that they are a heterogeneous group (Streib, 1982 cited by Ramashala), who differ in income, family arrangements, level of health, mobility, and attitudes and personality [age, gender, social networks]. This requires a profiling of older people in Eswatini to distinguish between the well and active older people, the disabled and the frail older persons, while capturing the necessary baseline on their living status, health condition and basic need. This has to be prioritised to inform the interventions required and the necessary capacities to be built. Further, Ramashala argues that providing supportive services to permit people to remain in their homes is considered the best option by many persons in the field of gerontology. For countries in Africa, it is perhaps the most viable option. He underscores that expensive institutional care is not an option for developing countries (Ramashala,n.d:15).

This paper supports Ramashala's suggestion and further argues that Eswatini established structures in the fight against HIV and AIDS, for example gogo centres, rural health motivators, etc which are still in existence and only need to be boosted with capacity and resources to continue the good work they are doing in the communities. Further, "the provision of care for older persons within their families and communities is not only sustainable and less costly but it allows for "ageing in place" which is in line with the United Nations Principles for Older Persons Resolution 46/91"(Dhemba, 2015). This will mean minimal uprooting of old people from their homes and institutionalising them, raising other considerations of what happens when they die? Custom dictates that family or next of kin become the custodian of the dead and make decisions pertaining to their burial including the sight and place. Therefore, it should also be emphasised that while there is a need to keep older persons in their families and social milieu, for "ageing in place" to occur, this can only be achieved if concerted effort is made to strengthen families and communities. It is also imperative to establish community centres where the right mix of health and other social services for older persons can be accessed and coordinated"(Dhemba, 2015).

\section{Options for policy and planning}

Ramashala (n.d.) recommends policy which takes into account a broad-based approach that distinguishes between the well and active elderly, the disabled elderly, and the frail elderly. Intervention options should consider inter-sectoral structures and multidisciplinary strategies to ensure that older people are well physically and psychologically and for as long as possible (ibid). Including, efforts towards empowering families and local communities with resources and technical assistance to care for older persons in the community (ibid). In addition, research including baseline studies need to be prioritised to "identify and modify, where possible, the broad range of high-risk situations that have long-term and devastating effects on older people" (ibid). Ultimately, "national governments should seek the active involvement of older people and their families, communities and non-governmental organizations in research, planning and policy implementation on all issues that are of concern to older people" (ibid).

For this to be possible local communities need to be empowered with resources and technical expertise to care for older persons in the community and have options for disabled older people who are living at home under the care of family members. Studies have shown that care for disabled older people, is around the clock, and a burden and major stressor to families and in some cases results in neglect and abuse (Ramashala, n.d.). Notably, Eswatini's response to the HIV and AIDS epidemic left a number of functioning programmes and structures at community level which can be empowered and up-scaled to take up the care of elderly people in their homes.

\section{Conclusions and recommendations}

While this paper acknowledges government action to establish old age homes due to pressure from reports of destitute older people received by the office of the Deputy Prime Minister and the Department of Social Welfare, the argument presented in this paper is that the strong cultural background of Eswatini should have informed the nature of support that is appropriate for its context. Eswatini has hastened the implementation of a very culturally sensitive programme without adequate research to establish the predictors for institutionalisation. There has been 
no adequate evidence based needs assessment of the elderly to inform the care and support system that is appropriate. This paper advocates for a care and support system that permits older people to remain in their homes - this is considered the most viable option by many authors in the field of gerontology. For countries in Africa, it is perhaps the better option. Expensive institutional care is the last resort for developing countries (Ramashala, n.d.).

Therefore, the study came up with the following recommendations:

- $\quad$ Research on older people is important and required to establish their real needs and to inform policy and programmes for older people, ensuring that their voices are captured in the study.

- A policy targeting older people is long overdue and needed to give direction on programmes and planning for older people. This should be informed by a profiling of older people to establish their varying needs and capabilities.

- More culturally sensitive approaches are needed for the care and support of older people, balancing care and support with familiar norms and values, and harmonising local traditional values with Western traditions of care and support.

- Use of already existing approaches of care and support which were established for HIV and AIDS coordination of home-based care need to be up-scaled and resourced with more financial and human resources. These are cost effective measures.

\section{References}

Chaves, L.J., and, Gi,C.A, Older people's concepts of spirituality, related to aging and quality of life, Ciênc. saúde coletiva vol.20 no.12 Rio de Janeiro Dec. 2015, http://dx.doi.org/10.1590/1413812320152012.19062014 , retrieved 11/11/2018.

Dhemba , J. and Dhemba , B., 2015, Ageing and Care of Older Persons in Southern Africa: Lesotho and Zimbabwe Compared, Social Work and Society Online International Journal, Vol. 13(2) 2015 https://www.socwork.net/sws/article/view/435/807, retrieved 07/11/2017.

Dlamini, L.S.,2003, Problems encountered by teenage mothers in the Southern Hhohho, https://doi.org/10.4102/hsag.v8i3.137, retrieved 07/11/2018.

Evans R., 2006, Helping Ourselves: Community Responses to AIDS in Swaziland, UNAIDS, Geneva, Switzerland, http://www.unaids.org, retrieved 19/12/2018.

Faller, J., and, Marcon,S.S., Health care and socio-cultural practices for elderly patients in different ethnic groups, Esc. Anna Nery vol.17 no.3 Rio de Janeiro July/Aug. 2013, http://www.scielo.br/scielo.php?

Government of Swaziland, 2013, Plan of Action 2013-2018, Mbabane, Swaziland, https://www.gov.sz.

Index Mundi, Swaziland economy profile $2018 \mathrm{https}$ :/www.indexmundi.com/swaziland/economy_profile.html, retrieved 2018/11/28

Kaleeba N., 2002, A Broken Landscape HIV \& AIDS in Africa, https://www,amazon.com retrieved 12/07/2017.

Kaseke, E., 1997, Social Security in Eastern and Southern Africa: Organisation, Issues and Concepts in Modern and Traditional Arrangements, Journal of Social Development in Africa (1977), 12, 2, 39-47

Khumalo T.F., Swaziland - effective Delivery of Public Education Services, The Open Society Initiative for Southern Africa, Johannesburg, South Africa.

Luppa M. et al (2009) Prediction of Institutionalization in the elderly. A systematic review.

Maeir K, 1992. Free-market Africa's age of disrespect: Traditional care of the elderly is declining as Western ways take their toll. Karl Maier reports from Accra, BST, The Independent Online. http://www.independent.co.uk/news/world/free-market-africas-age-of-disrespect-traditional-care-of-theelderly-is-declining-as-western-ways-1532764.html retrieved 06/09/2017.

Manzini City Council, 2011, Rates and Property Evaluation, http://www.mzcitycouncil.sz/index.php/treasurydepartment/rates-and-property-valuation.

Nicholl,C.G., and Wilson,K.J., 2012, Lecture Notes: Elderly Care Medicine, John Wiley and Sons Ltd, https://books.google.com/books?id...., retrieved 15/11/2018.

Observer on Saturday, Mankayane Old Age Home, 10 June 2017, https:/www.pressreader.com, retrieved $15 / 06 / 2017$.

Ratlebjane M., How 'black tax'cripples our youth's aspirations, Mail \& Guardian, 30 October 2015 http://mg.co.za/article/2015-10-29-how-black-tax-cripples-our-youth-aspirations.

SHAH (n.d.) Home Based Care, website www.swazilandhospiceathome.org/programmes/HomeBasedCare.php

Swaziland Government, 2016, Ministry of Economic Planning and Development, The National Development Strategy 2022 (NDS),www.undp.org.

Social Protection Systems and Economic Policy Research Institute (SPS \& EPRI), 2016, Old Age Grants (OAG) in Swaziland, Mbabane, Swaziland.

The Central Statistical Office (CSO) Swaziland, Census 2017 Preliminary results, www.swazistats,org.sz, retrieved 30/11/2018. 
The CentralStatistical Office (CSO) Swaziland, Demographic Indicators 2000-2030, www.swazistats.org.sz, retrieved 30/11/2018.

The Central Statistical Office (CSO), 2017, The 2017 Population and Housing Census Preliminary Results, United Nations Population Fund.

The World Bank, 2012, Swaziland Using Public Transfers to Reduce Extreme Poverty, Washington D.C.

Umchumanisi Link Action Research Network (ULARN), 2003, Social Protection of The Elderlyin Swaziland, A Research Report,Submitted to The Coordinating Assembly of NGOs (CANGO), Mbabane, Swaziland, https://sarpn.org, retrieved 25/07/2017.

United Nations Educational, Scientific and Cultural Organiation (UNESCO), 1995, Building Peace in the minds of men and women, www.unesco.org, retrieved 20/11/2018.

United Nations Statistics Division, 2016, "Swaziland age dependency ratio" is based on the demographic and social statistics', https://unstats.un.org, Retrieved 11/11/2018.

World Bank, 2018, Global Economic Prospects, Volume 3, June 2011, https:://openknowledge.worldbank.org, retrieved 11/11/2018.

World Health Organisation, 2016, Life expectancy of Swaziland, https://countryeconomy.com,retrieved $11 / 12 / 2018$

World population 2018, CountryMeters.info, https://countrymeters.info > world, retrieved 30/11/2018 